\title{
Ağrısız Dokunsal Uyaranlar ve Uyku
}

\section{Non-Painful Tactile Stimuli and Sleep}

\author{
Gonca İnanç, Murat Özgören*, Adile Öniz* \\ Dokuz Eylül Üniversitesi Tıp Fakültesi, Biyofizik Anabilim Dalı, Izmir, Türkiye \\ *Dokuz Eylül Üniversitesi Tıp Fakültesi, Biyofizik Anabilim Dalı, Uyku ve Bilinç Durumları Teknolojisi Uygulama ve Araştırma Merkezi, Izmir, Türkiye
}

\section{Özet}

Giriş: Çalışmanın amacı uyku sırasında uygulanan ağrısız dokunsal uyaranlara karşı beyinde oluşan elektrofizyolojik yanıtları incelemektir.

Gereç ve Yöntem: Çalışmaya 15 sağlıklı gönüllü birey (8 kadın, yaş ortalamaları: 22,13 $\pm 1,41)$ katılmıştır. Kayıtlar, NuAmps 40 kanallı kayıt sistemi, pnömatik uyarıcı ünitesi (Somatosensory Stimulus Generator 4-D Neuroimaging), Embedded Microcontroller Stimulation Unit (EMISU), video kayıt sistemi ve analiz bilgisayarı gibi ek teknik donanım kullanılarak gerçekleştirilmiştir. Sabit basınçta (140 kPa) ağrısız uyaranlar sağ el işaret ve orta parmaklarına uygulanmıştır. Parmaklardan birine seyrek uyaran olarak uygulama yapılmıştır (\%25). Sürekli elektroensefalografi (EEG), elektrookülografi (EOG), elektromiyografi (EMG) kayıtları Amerikan Uyku Tıbbı Akademisi (AASM) kurallarına göre uyku evrelerine ayrılmıştır. Somatosensoriyel öncelikli alanlar olarak $C 3$ ve $C 4$ elektrotlarında meydana gelen yanıtlar incelenmiştir. İstatistiksel analizlerde bağımlı gruplarda t testi kullanılmıştır.

Bulgular: Yüzeyel ve derin uykuda hem seyrek hem de sık uygulanan uyaranlara karşı N100, P200, N300, P450, N550, P900 ve Ngeç dalga formları açıkça gözlenmiştir. Sağ elde, her iki uyarana karşı elde edilen yanıtlar birbirine benzer olarak bulunmuştur.

Sonuç: Uykuda beyin yanıtlılı̆ı sürmekte ancak elektrofizyolojik yanıt paterni değişiklik göstermektedir. Ayrıca, uykuda yönlendirilmiş dikkat, uyaran ayırt etme, çalışan bellek gibi süreçlerin istemli olarak kullanılamaması her iki uyarana karşı olan yanıtın birbirine benzer olmasına neden olmaktadır. (JTSM 2014;1:9-15)

Anahtar Kelimeler: Uyku, elektroensefalografi, dokunsal olay ilişkili potansiyel, elektrofizyoloji

\section{Summary}

Introduction: The aim of this study is to examine electrophysiological responses in the brain to painless somatosensory stimulation during sleep. Materials and Methods: Fifteen healthy volunteers ( 8 female, with mean age: $22.13 \pm 1.41$ ) participated in the study. Recordings were carried out using NuAmps 40 channeled recording system, pneumatic stimulation unit (Somatosensory Stimulus Generator 4-D Neuroimaging), Embedded Microcontroller Stimulation Unit (EMISU), and additional equipment such as video recording system and analysis computer. Painless air pressure stimulation was applied at constant pressure rate to the fore and middle fingers of the right hand. Infrequent oddball stimulation was applied to one of the fingers (\%25 of the time). Continuous electroencephalography (EEG), electrooculography (EOG) and electromyography (EMG) recordings were sorted into sleep phases according to the guidelines set by the American Academy of Sleep Medicine (AASM). Responses recorded from the $\mathrm{C} 3$ and $\mathrm{C} 4$ electrodes were examined as somatosensory regions of priority. Paired samples T-tests were used for statistical analysis.

Results: N100, P200, N300, P450, N550, P900 Nlate wave forms were clearly observed for both frequent and infrequent stimuli in light and deep sleep. Responses to both target and non-target stimuli on the right hand were found to be similar to each other.

Discussion: Brain responsiveness continues in sleep; however electrophysiological response pattern can vary. Furthermore as processes such as directed attention, stimulus discrimination and working memory cannot be voluntarily employed during sleep; responses to both kinds of stimuli are similar to one another. (JTSM 2014;1:9-15)

Key Words: Sleep, electroencephalography, somatosensory event related potential, electrophysiology

Yazışma Adresi/ Address for Correspondence: Dr. Adile Öniz, Dokuz Eylül Üniversitesi Tıp Fakültesi, Biyofizik Anabilim Dalı, Uyku ve Bilinç Durumları Teknolojisi Uygulama ve Araştırma Merkezi, İzmir, Türkiye Tel.: +90 2324124498 E-mail: adile.oniz@deu.edu.tr Geliş Tarihi/Received: 08.12.2013 Kabul Tarihi/Accepted: 16.03.2014 


\section{Giriş}

Tarih boyunca uyku ile ilgili çalışmalara rastlamak mümkündür. Richard Caton'ın tavşan beyninde elektriksel ritimlerin varlığını göstermesinden sonra Hans Berger insan beyninde yaptığı çalışmalar ile uyku ve uyanıklık arasındaki farkları göstermiştir. 1938 yılında Loomis ve ark.'nın yaptıkları çalışmalar ile polisomnografinin (PSG) temeli atılmıştır (1).

PSG ile uykuda meydana gelen fizyolojik, psikolojik, patolojik değişiklikleri ve uykunun yapısını araştırmak mümkündür. PSG'de elektroensefalografi (EEG), elektrookülografi (EOG) ve elektromiyografi (EMG) uyku evrelerinin belirlenmesinde kullanılan temel bileşenlerdir. Bu bileşenlerin dışında solunumsal parametreler, kan basıncl, horlama, vücut pozisyonu gibi parametreler ise uyku bozukluklarının tanımlanmasında kullanılmaktadır (2). PSG sistemi ile alınan kayıtlar standart uyku skorlama yöntemi ile evrelere ayrılır. Günümüzde uyku evrelerini belirlemede Amerikan Uyku Tıbbı Akademisi (AASM, American Academy of Sleep Medicine) kuralları kullanılmaktadır (3).

Uyanıklık, uyku, koma, anestezi gibi farklı bilinç durumlarında beynin kendiliğinden (spontan) gelişen elektriksel etkinlikleri elektroensefalografi ile takip edilebilir. Beynin Etiği kitabında doğum, fetusun 5-6 haftalık döneminde (40-43 gün) beynin ilk elektriksel aktivitesinin saptanmasıyla tanımlanırken; ölüm ise tüm dünyada beynin elektriksel aktivitesinin durması ile tanımlanmaktadır (4).

Beyin dinamik çalışan ve iç, dış uyaranlarla uyarılabilir bir organdır. Beynin işlerliğini anlamak için beş duyuya ait uyaranlarla bilişsel işlevleri ölçmeye ait deney desenleri ile elektrofizyolojik yanıtlardaki değiş̧im incelenebilir. En sık kullanılan deney desenleri uyarılma potansiyelleri ve olay ilişkili potansiyellerdir. Olay ilişkili potansiyellerden en sık kullanılan ise seyrek uyaran deney desenidir (5). Dokunsal uyaranlar ile yapılan çalışmalar daha çok ağrılı uyaranlar, laser uyaranı veya vibrasyondan oluşmaktadır $(6,7)$. Uyanık süreçlerde uygulanarak temel veri gruplarının oluştuğu ve klasik kullanımda olan bu ölçümlerin uyku, anestezi altında beyin, koma vb. farklı bilinç durumlarında kullanılması ile beynin bilgi işlemleme araştırmaları son yıllarda hız kazanmıştır. Uyku sırasında beynin dış dünya ile iletişiminin kesilmediği ve uyanıklıktan farklı olarak işlendiği bilinmektedir (8). Literatürde uykuda bilgi işlemleme ile yapılan çalışmalarda genellikle uyarılma potansiyelleri ve olay ilişkili potansiyeller kullanılmakta ve uyku sırasında uyaranlara verilen beyin yanıtları temel alınarak incelenmektedir.

$\mathrm{Bu}$ çalışmada amaç; uyku süreçlerinde seyrek uyaran deney desenine karşı beyin yanıtlarının incelenmesidir.

\section{Gereç ve Yöntem}

Çalışma için Dokuz Eylül Üniversitesi Girişimsel Olmayan Araştırmalar Etik Kurulu'ndan izin alınmıştır. Çalışmaya sağ eli baskın 15 sağlıklı gönüllü (8 kadın, yaş ortalaması:

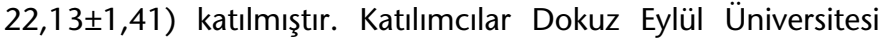
Tıp Fakültesi, Biyofizik Anabilim Dalı, Uyku Dinamiği Araştırma Laboratuvarı'nda bir gece uyumuşlardır ve ilk gece kayıtlarıdır. Gönüllülere uygulanan testler; Edinburgh El Tercihi Testi, uyku kalitelerini ve gündüz aşırı uykululuk durumlarını değerlendirmek için ise Pittsburgh Uyku Kalite İndeksi (PUKi), Epworth Uyku Skalası, ruhsal açıdan çalışmaya katılmalarına engel olabilecek sorunları belirlemek amacıyla STAI Form TX-1 (Anlık Anksiyete
Ölçeği) ve SCL-90R (Belirti Tarama) testleri uygulanmıştır. Herhangi bir nörolojik, psikiyatrik, kronik ve uyku bozukluğu tanısı alan bireyler çalışmadan dışlanmıştır.

Katılımcılar elektromanyetik dalga ve sesten yalıtılmış özel bir odada uyumuşlardır. Kayıt sırasında oda, katılımcıların bilgisi ve izni dahilinde kamera ile izlenmiştir.

Kayıtlar, NuAmps 40 kanallı kayıt sistemi, gömülü mikrokontrollü uyarı ünitesi (Embedded Microcontroller Stimulation UnitEMISU), pnömatik uyarıcı ünitesi (Somatosensory Stimulus Generator 4-D Neuroimaging), video kayıt sistemi ve EEG bonesi, analiz bilgisayarı gibi ek teknik donanım kullanılarak gerçekleştirilmiştir. Katılımcıların kafalarına uygun büyüklükteki EEG kepi (Quick Cap, Neuromedical Supplies) kullanılmış ve uluslararası Jasper 10-20 sistemine göre bireylerin kafalarına yerleştirilmiştir. Kepte bulunan elektrotlar ile saçlı deri arasındaki iletkenliği sağlamak için elektrojel (ECI Electro-Gel, ElectroCap International, Inc., ABD) kullanılmıştır. EEG elektrotları kulak memelerine takılan elektrotlar ile referanslanmıştır $[(A 1+A 2) / 2]$. Kayıt sırasında elektrotların empedansları ortalama 5 kOhm civarında tutulmuştur. Sürekli EEG kaydı 1 kHz'lik örneklem hızı ile alınmıştır.

Ağrısız dokunsal uyaranlar için pnömatik uyarıcı ünitesi (4-D Neuroimaging Somatosensory Stimulus Generator) kullanılmıştır. Uyaranların uygulanabilmesi için parmağa temas yüzeyinde ortalama $8-9 \mathrm{~mm}$ çapında hareketli zar bulunan klipsler kullanılmıştır. Bu zar katılımcıların sağ el işaret ve orta parmak pulpalarına gelecek şekilde yerleştirilmiştir. Klipsler izole oda dışında bulunan pnömatik uyarıcı ünitesine, ünite ise kuru hava tüpüne bağlıdır. MATLAB programında hazırlanmış deney desenine göre katılımcılara ağrısız dokunsal uyaranlar uygulanmıştır. Çalışmada seyrek uyaran deney deseni kullanılmıştır. Katılımcılara her bir blokta 120 uyaran gönderilmiştir ve blok gece boyunca tekrarlanmıştır. Uyaranlar ileti yollarının aynı olması nedeniyle el işaret ve orta parmağına uygulanmıştır. Uyaranların \%25'i seyrek uyaran olarak bir parmağa, \%75'i sık uyaran olarak diğer parmağa uygulanmıştır. Uyaranlar arası süre (ISI) 3-3,5 saniye olarak seçkisiz şekilde düzenlenmiştir (Şekil 1).

EEG kayıtları kayıt sonrası değerlendirilmiştir. Uyku kayıtlarının skorlaması uluslararası Amerikan Uyku Tıbbı Akademisi (AASM, American Academy of Sleep Medicine) kurallarına göre yapılmıştır. Otuz saniyelik zaman dilimleri göz ile tek tek incelenmiş ve evreler belirlenmiştir. N1 ve N2 yüzeyel uyku, N3 ise derin uyku olarak değerlendirilmiştir. Evreleme işleminden sonra evrelere denk gelen seyrek ve sık uyaranlar ayrılmıştır. Her bir uyku evresi için uyaran öncesi 500 ms ve uyaran sonrası 2000 ms'lik kısmı içine alan süpürümler oluşturulmuştur. Söz konusu süpürümlerde EOG kanalında genliği $\pm 100 \mu V^{\prime}$ dan yüksek genliğe sahip sinyaller ayıklanmıştır. Bütün katılımcılar için elde edilen kayıtlar yatay eksen temel alınarak düzeltilmiş ve 0,5-30 Hz bant geçiren filtre ile filtrelenmiştir. Daha sonra her bir katılımcı ve uyku evresi için ortalama dosyaları oluşturulmuştur. On beş katılımcıya ait seyrek ve sık uyaranlara ait grup ortalamaları ayrıca oluşturulmuştur. Elektrofizyolojik yanıtların genliklerinin ölçümünde 0-2000 ms arasındaki en büyük genlikli yanıtlar $\mu \mathrm{V}$ cinsinden ölçülmüş ve değerlendirilmiştir. 
İstatistiksel analizlerde SPSS 16 programı, bağımlı gruplarda t testi kullanılmıştır. Kayıtlar kafa üzerinde 40 kanaldan alınmıştır. Ancak ağrısız dokunsal uyaranlar açısından öncelikli alanlar olan $C_{3}$ ve $C_{4}$ elektrotlarına ait olay ilişkili potansiyeller incelenmiştir.

\section{Bulgular}

Çalışmada tüm gece uyku kayıtları elde edilmiştir. Ortalama uyku süresi yedi buçuk saat olup, en kısa kayıt süresi altı, en uzun kayıt süresi sekiz saattir. Sağ ele uygulanan seyrek ve sık uyaranlara karşı oluşan yanıtların genlik değerleri yüzeyel ve derin uykuda kendi içinde incelenmiştir. Oluşan elektrofizyolojik beyin yanıtlarında yedi bileşen belirgin olarak ortaya çıkmıştır.
Bu bileşenler; N100, P200, N300, P450, N550, P900 ve Ngeç'tir (Şekil 2).

\section{a) Yüzeyel Uyku}

Yüzeyel uykuda, $C_{3}$ ve $C_{4}$ elektrotlarında sağ ele uygulanan seyrek uyaranlara karşı oluşan yanıtların ortaya çıkma süreleri incelendiğinde N100 yanıtı uyarandan 94 ile 208 ms sonra, P200 yanitı uyarandan 166 ile 262 ms sonra, N300 yanit uyarandan 306 ile 386 ms sonra, P450 yanıtı uyarandan 420 ile 542 ms sonra, N550 yanıtı uyarandan 474 ile 688 ms sonra, P900 yanıtı uyarandan 640 ile 878 ms sonra, Ngeç yanıt uyarandan 968 ile 1200 ms sonra gözlenmiştir. Sık uyaranlara karşı oluşan yanıtlar incelendiğinde ise N100 yanıtı uyarandan

\begin{tabular}{|c|c|c|c|c|c|c|c|c|c|}
\hline \multirow{2}{*}{$C_{3}$} & Y & Seyrek Uyaran & $122-208$ & $172-262$ & $310-360$ & $436-494$ & $474-684$ & $674-878$ & $980-1200$ \\
\hline & $\mathrm{D}$ & Sık Uyaran & $134-166$ & $176-230$ & $278-388$ & $408-550$ & $522-752$ & $630-938$ & $906-1098$ \\
\hline \multirow{4}{*}{$\mathrm{C}_{4}$} & \multirow{2}{*}{ Y } & Sık Uyaran & $96-208$ & $156-302$ & $296-376$ & $424-526$ & $504-748$ & $640-782$ & $1040-1176$ \\
\hline & & Seyrek Uyaran & $94-198$ & $166-234$ & $306-386$ & $420-542$ & $474-688$ & $640-878$ & $968-1174$ \\
\hline & \multirow{2}{*}{$\mathrm{D}$} & Sık Uyaran & $102-160$ & $182-224$ & $296-404$ & $414-554$ & $496-758$ & $646-932$ & $910-1100$ \\
\hline & & Seyrek Uyaran & $96-272$ & $170-342$ & $288-372$ & $462-532$ & $528-706$ & $618-796$ & $958-1120$ \\
\hline
\end{tabular}

Tablo 2. Yüzeyel uykuda (N1 ve N2) sağ ele uygulanan seyrek (t) ve sık (nt) uyaranlara karşı oluşan yanıtların ortalama genlik değerleri ve standart sapmaları. Genlik değerleri $\mu \mathrm{V}$ cinsindendir.

\section{Yüzeyel Uyku}

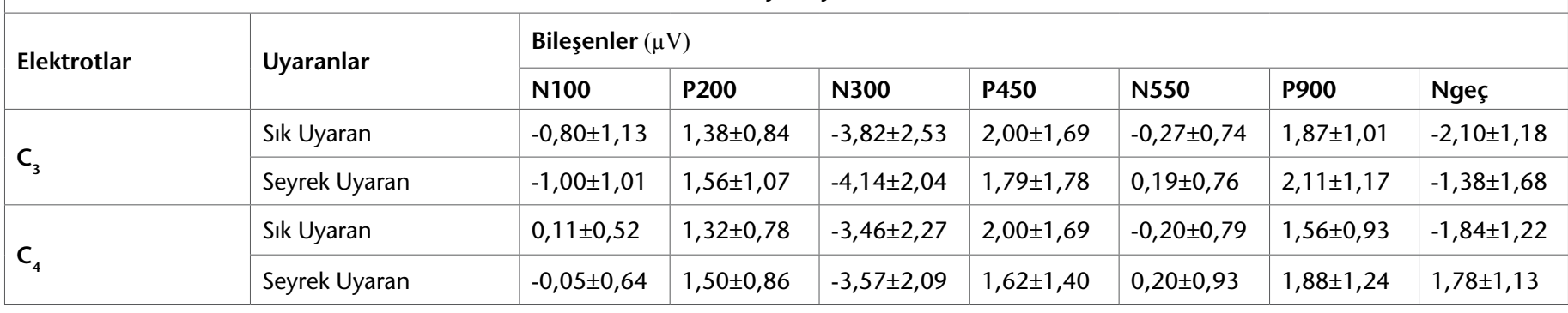

Tablo 3. Derin uykuda (N3) sağ ele uygulanan seyrek (t) ve sık (nt) uyaranlara karşı oluşan yanıtların ortalama genlik değerleri ve standart sapmaları. Genlik değerleri $\mu \mathrm{V}$ cinsindendir.

\begin{tabular}{|l|l|l|l|l|l|l|l|l|}
\hline \multicolumn{2}{|l|}{ Elektrotlar } & \multirow{2}{*}{ Uyaranlar } & \multicolumn{2}{|l|}{ Bileşenler $(\mu \mathrm{V})$} & Nyku \\
\cline { 2 - 9 } & & N100 & P200 & N300 & P450 & N550 & P900 & Ngeç \\
\hline \multirow{2}{*}{$C_{3}$} & Sik Uyaran & $-1,59 \pm 1,91$ & $1,34 \pm 1,97$ & $-5,89 \pm 3,10$ & $3,27 \pm 2,48$ & $0,61 \pm 2,47$ & $3,41 \pm 2,35$ & $-4,59 \pm 2,92$ \\
\cline { 2 - 9 } & Seyrek Uyaran & $-1,71 \pm 2,55$ & $1,90 \pm 2,44$ & $-5,74 \pm 2,96$ & $4,61 \pm 1,85$ & $0,61 \pm 2,42$ & $2,49 \pm 2,11$ & $4,28 \pm 2,39$ \\
\hline \multirow{2}{*}{$C_{4}$} & Sik Uyaran & $-0,74 \pm 1,80$ & $1,88 \pm 1,58$ & $-4,78 \pm 3,03$ & $2,35 \pm 2,07$ & $0,23 \pm 2,35$ & $3,13 \pm 1,92$ & $-3,50 \pm 2,67$ \\
\cline { 2 - 9 } & Seyrek Uyaran & $-0,90 \pm 1,76$ & $1,83 \pm 2,40$ & $-4,90 \pm 2,63$ & $3,60 \pm 1,77$ & $0,76 \pm 1,96$ & $3,11 \pm 2,06$ & $4,32 \pm 2,35$ \\
\hline
\end{tabular}


96 ile 234 ms sonra, P200 yanıtı 156 ile 302 ms sonra, N300 yanıtı 290 ile 376 ms sonra, P450 yanıtı 404 ile 526 ms sonra, N550 yanitı 504 ile 748 ms sonra, P900 yanıtı 640 ile 844 ms sonra ve Ngeç yanıtı 1012 ile 1184 ms sonra gözlenmiştir (Tablo 1). Yüzeyel uykuda sağ ele uygulanan seyrek ve sık uyaranlara karşı beyinde oluşan yanıtların ortaya çıkma süreleri arasında istatistiksel olarak anlamlı farklılık bulunmamıştır.

Yüzeyel uykuda, C3 ve C4 elektrotlarında sağ ele uygulanan seyrek uyaranlara karşı oluşan yanıtların genlikleri incelendiğinde N100 yanıtının genliği ortalama $-0,05$ ile $-1,00 \mu \mathrm{V}$ arasında, P200 yanıtının genliği ortalama 1,50 ile 1,56 $\mu \mathrm{V}$ arasında, N300

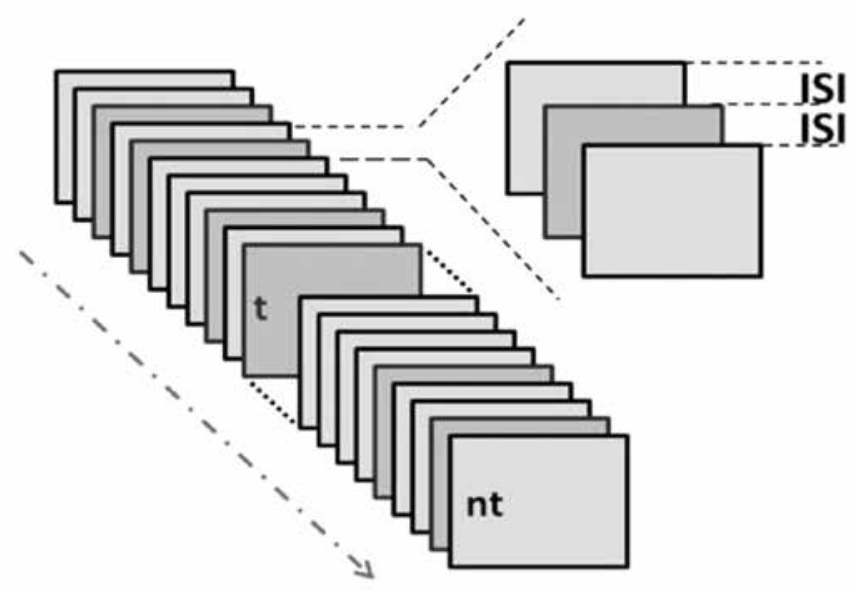

Şekil 1. Seyrek uyaran paradigmasında uyaranların uygulanma dizilimi (nt: sık uyaran, t: seyrek uyaran).

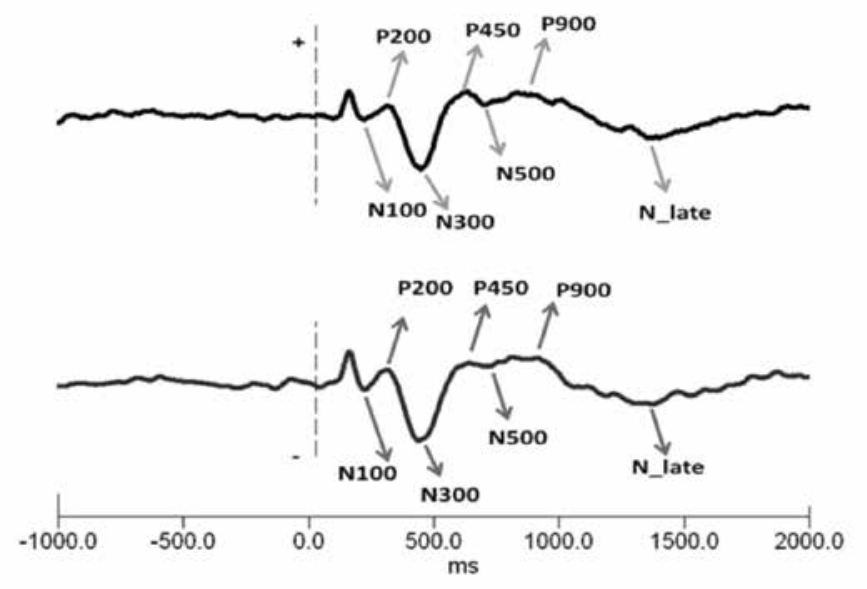

Şekil 2. Yüzeyel uykuda sağ ele uygulanan seyrek ve sık uyaranlara karşı oluşan yanıtların gösterimi, $\mathrm{C}_{3}$ elektrodundaki potansiyeller gösterilmektedir $(n=15)$, Uyaran anı " 0,0 " noktasındaki kesikli çizgi ile gösterilmektedir. Yatay eksen uyaran öncesi 1000 ms, uyaran sonrası 2000 ms olmak üzere zaman eksenidir. Düşey eksen genlik $(\mu \mathrm{V})$ değerlerini göstermek üzere alt taraf negatif, üst taraf pozitif yönü göstermektedir. yanıtının genliği ortalama $-3,57$ ile $-4,14 \mu \mathrm{V}$ arasında, P450 yanıtının genliği ortalama 1,62 ile 1,79 $\mu \mathrm{V}$ arasında, N550 yanıtının genliği ortalama 0,19 ile $0,20 \mu \mathrm{V}$ arasında, P900 yanıtının genliği ortalama 1,88 ile $2,11 \mu \mathrm{V}$ arasında ve $\mathrm{Ngeç}$ yanıtının genliği ortalama -1,38 ile 1,78 $\mu \mathrm{V}$ arasında değiştiği gözlenmiştir. Sık uyaranlara karşı oluşan yanıtların genlikleri incelendiğinde ise N100 yanıtının genliği ortalama $-0,80$ ile $0,11 \mu \mathrm{V}$ arasında, P200 yanıtının genliği ortalama 1,32 ile 1,38 $\mu \mathrm{V}$ arasında, N300 yanıtının genliği ortalama $-3,46$ ile $-3,82 \mu \mathrm{V}$ arasında, P450 yanıtının genliği ortalama 2,00 $\mu \mathrm{V}^{\prime}$ da, N550 yanıtının genliği ortalama $-0,20$ ile $-0,27 \mu \mathrm{V}$ arasında, P900 yanıtının genliği ortalama 1,56 ile $1,87 \mu \mathrm{V}$ arasında ve $\mathrm{Ngeç}$ yanıtının genliği $-1,84 \mu \mathrm{V}$ ile $-2,10 \mu \mathrm{V}$ arasında gözlenmiştir (Tablo 2).

Yüzeyel uykuda sağ ele uygulanan seyrek (t) ve sık (nt) uyaranlara karşı oluşan yanıtlar arasında istatistiksel olarak anlamlı farklılık bulunmamıştır (Şekil 3).

\section{b) Derin Uyku}

Derin uykuda, $C_{3}$ ve $C_{4}$ elektrotlarında sağ ele uygulanan seyrek uyaranlara karşı oluşan yanıtların ortaya çıkma süreleri incelendiğinde N100 yanıtı uyarandan 96 ile 252 ms sonra, P200 yanıtı uyarandan 170 ile 342 ms sonra, N300 yanıtı uyarandan 288 ile 392 ms sonra, P450 yanıtı uyarandan 458 ile 532 ms sonra, N550 yanıtı uyarandan 528 ile 706 ms sonra, P900 yanıtı uyarandan 618 ile 796 ms sonra, Ngeç yanıtı uyarandan 958 ile 1190 ms sonra gözlenmiştir. Sık uyaranlara karşı oluşan yanıtların ortaya çıkma süreleri incelendiğinde ise 102 ile 166 ms sonra N100 yanıtı, 176 ile 230 ms sonra P200 yanıtı, 278 ile 404 ms sonra N300 yanıtı, 408 ile 554 ms sonra P450 yanıtı, 496 ile 758 ms sonra N550 yanıtı, 630 ile 938 ms sonra P900 yanıtı ve 906 ile 1100 ms sonra Ngeç yanıtı gözlenmiştir (Tablo 3). Derin uykuda sağ ele uygulanan seyrek ve sık uyaranlara karşı beyinde oluşan yanıtların ortaya çıkma süreleri arasında istatistiksel olarak anlamlı farklılık bulunmamıştır.

Derin uykuda, $\mathrm{C}_{3}$ ve $\mathrm{C}_{4}$ elektrotlarında sağ ele uygulanan seyrek uyaranlara karşı oluşan yanıtların genlikleri incelendiğinde N100 yanıtının genliği ortalama $-0,90$ ile $-1,71 \mu \mathrm{V}$ arasında, P200 yanıtının genliği ortalama 1,83 ile $1,90 \mu \mathrm{V}$ arasında, N300 yanıtının genliği ortalama $-4,90$ ile $-5,74 \mu \mathrm{V}$ arasında,

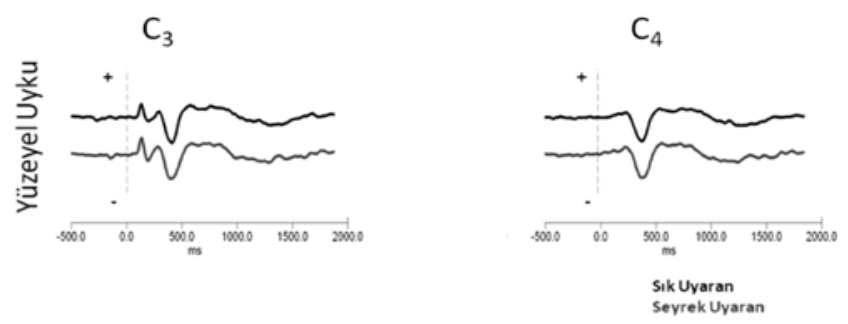

Şekil 3. Yüzeyel uykuda sağ ele uygulanan seyrek ve sık uyaranlara karşı oluşan beyin yanıtları $C_{3}$ ve $C_{4}$ elektrotlarındaki potansiyeller gösterilmektedir $(n=15)$, Uyaran anı " 0,0 " noktasındaki kesikli çizgi ile gösterilmektedir. Yatay eksen uyaran öncesi 500 ms, uyaran sonrası 2000 ms olmak üzere zaman eksenidir. Düşey eksen genlik $(\mu \mathrm{V})$ değerlerini göstermek üzere alt taraf negatif, üst taraf pozitif yönü göstermektedir. 
P450 yanıtının genliği ortalama 3,60 ile 4,61 $\mu \mathrm{V}$ arasında, N550 yanıtının genliği ortalama 0,61 ile $0,76 \mu \mathrm{V}$ arasında, P900 yanıtının genliği ortalama 2,49 ile 3,11 $\mu \mathrm{V}$ arasında ve Ngeç yanıtının genliği ortalama $-4,28$ ile $-4,32 \mu \mathrm{V}$ arasında gözlenmiştir. Sık uyaranlara karşı oluşan yanıtların genlikleri incelendiğinde ise N100 yanıtı $-0,74$ ile $-1,59 \mu \mathrm{V}$ arasında, P200 yanıtının genliği ortalama 1,34 ile 1,88 $\mu \mathrm{V}$ arasında, N300 yanıtının genliği ortalama $-4,78$ ile $-5,89 \mu \mathrm{V}$ arasında, P450 yanıtının genliği ortalama 2,35 ile $3,27 \mu \mathrm{V}$ arasında, N550 yanıtının genliği ortalama 0,23 ile $0,61 \mu \mathrm{V}$ arasında, P900 yanıtının genliği ortalama 3,13 ile $3,41 \mu \mathrm{V}$ arasında ve Ngeç yanıtının genliği $-3,50 \mu \mathrm{V}$ ile $-4,59 \mu \mathrm{V}$ arasında gözlenmiştir (Tablo 3).

Derin uykuda sağ ele uygulanan seyrek (t) ve sık (nt) uyaranlara karşı oluşan yanıtlar arasında istatistiksel olarak anlamlı farklılık bulunmamıştır (Şekil 4).

Yüzeyel ve derin uykuda elektrofizyolojik yanıtların oluşum biçimleri değişiklik göstermesine rağmen, hem seyrek hem de sık uyaranlara karşı ortaya çıkan yanıtlardaki dalga formları birbirine benzer bulunmuştur.

\section{Tartışma}

Literatürde uyanıklık sürecinde seyrek uyaran deney deseninin kullanıldığı çalışmalarda görülen P300 bileşeninin uyku başlangıcı ile kaybolduğu ve yerine NREM'de yerini uykuya özel bileşenler olan P220, N350, P450, N550 ve P900'a bıraktığı bildirilmiştir (9-11). Çalışmada literatür ile uyumlu beyin yanıtları gözlenmiştir. Uyku sürecinde beyin dinamiklerinde meydana gelen değişikliklerin uyanıklıktaki ile aynı olmadığı, beyin ile dış çevre arasındaki fonksiyonel kopukluklar ile ilgili farklı teorilerin ileri sürüldüğü bildirilmiştir (12). Uykuda, duyusal uyaranlara karşı farklılıkların oluşma nedeni olarak, uyaranlara ilgi ve dikkatin uykuda tam olarak ayrılamaması gösterilmiştir $(13,14)$. Aynı uyaranın tekrar tekrar uygulandığı çalışmada N1 yanıtının genliğinde azalma olduğu gösterilmiştir (14). Magnetoensefalografi (MEG) ile yapılan bir çalışmada ise N100 bileşenin işitsel uyaranlara özel karakteristik kodlama ile ilgili olduğu iddia edilmiştir (15). Uyku iğciklerinin bulunduğu Evre 2'de N100 genliğinin küçüldüğü de belirtilmiştir (16).

P200 bileşenin yavaş dalga uykusu sırasında diğer evrelere göre daha büyük olduğu gösterilmiş ve altında yatan

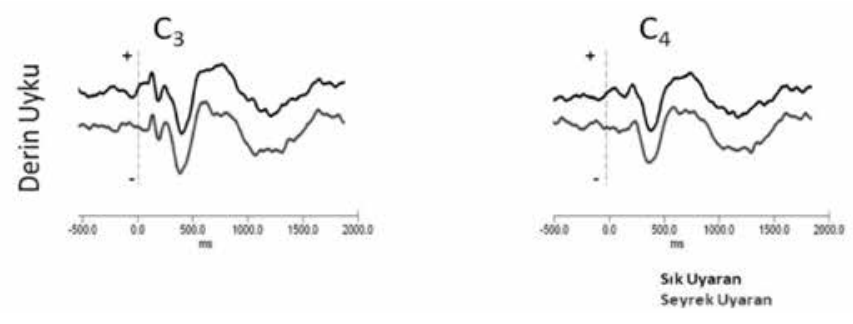

Şekil 4. Derin uykuda sağ ele uygulanan seyrek ve sık uyaranlara karşı oluşan beyin yanıtları $C_{3}$ ve $C_{4}$ elektrotlarındaki potansiyeller gösterilmektedir $(n=15)$. Uyaran anı " 0,0 " noktasındaki kesikli çizgi ile gösterilmektedir. Yatay eksen uyaran öncesi 500 ms, uyaran sonrası 2000 ms olmak üzere zaman eksenidir. Düşey eksen genlik $(\mu \mathrm{V})$ değerlerini göstermek üzere alt taraf negatif, üst taraf pozitif yönü göstermektedir. mekanizmanın uykunun derinleşmesi ile arttığı yorumu yapılmıştır $(17,18)$. P220 genliğinin gece boyunca stabil bir halde görüldüğü belirtilmiştir (19). Literatürde seyrek uyaran deney deseninin kullanıldığı çalışmalarda, bu yanıtın hedef olmayan işitsel uyaranlara karşı daha zayıf olarak ortaya çıktığı, hedef uyaranlara karşı ise daha büyük genlikli elde edildiği bildirilmiştir. Hedef olmayan uyaranlara karşı daha zayıf P200 elde edilmesinin nedeni olarak, aynı uyaranın kısa aralıklarla ve sıkça tekrarlanması olabileceği bildirilmiştir (20). Çalışmada seyrek ve sık uyaranlara karşı oluşan P200 yanıtının genliğinde anlamlı farklıık bulunmamıştır.

Olay ilişkili potansiyel çalışmalarında Evre 1, Evre 2 ve yavaş dalga uykusunda iki negatif bileşen olan N300 ve N550 bileşenleri kayıt edilmiştir (21). N300 yanıtı uyaranın anlamsal içeriği ile ilişkili bulunurken, N550 yanıtı ise uyaranın fiziksel özelliği ile ilişkili bulunmuştur (22). Uyku yoksunluğu sonrasında yapılan bir çalışmada N300, N550 bileşenlerinin genliklerinin arttığı gösterilmiştir. Bu nedenle bu dalga formlarındaki genlik artışının, baskılayıcı süreçleri yansıtıyor olabileceği yorumu yapılmıştır (23). N300 bileşeninin uyaranın özelliklerine ve yoğunluğuna duyarlı olduğu ileri sürülmüştür (24). Katılımcılara kendi isimlerinin ve diğer kelimelerin olduğu deney deseninde NREM'de N350 ve N550 yanıtlarının hedef uyaranlarda hedef olmayan uyaranlardan büyük bulunmuştur. Bu sonuç uykuda uyaranları tanıma kapasitesini içerdiğinin kanıtı olarak gösterilmiştir (25).

N550 yanıtı K-komplekslerinin negatif bileşeni olarak kabul edilmiştir. Bunun nedeni olarak da K-kompleksleri ortalamadan çıkarıldığında bu bileşenin büyük ölçüde küçüldüğü ya da yok olduğu belirtilmiştir $(26,27)$. N550 yanıtının, K-komplekslerinin negatif bileşeni ile ilişkili olduğu ve $\mathrm{K}$ komplekslerinin de özellikle yavaş dalga uykusu öncesinde sıklaştığı bildirilmiştir (28). Bazı çalışmalarda kısa ISI sürelerinde K-komplekslerinin ortaya çıkmadığı gösterilmiştir $(29,30)$. Uyaranlar arası süre kısa olduğunda N550 genliğinin zayıfladığı ve 1,5 saniyelik uyaranlar arası süre ile N550 yanıtının ortaya çıkmadığı belirtilmiştir (31). N550 bileşenlerinin K-kompleksleri ile bağlantılı olduğunu ileri sürmüşlerdir (32). N550'nin uyaranın miktarı ile ilgili olduğu ileri sürülmüştür (33). Yavaş dalga uykusunda ve Evre 2'de N550 bileşeninde farklılıklar olduğu bildirilmiş ve farklı kaynaklar ile farklı yollar izlendiği, farklı aktivitelerin yansıtıldığı ileri sürülmüştür (34).

P450 bileşeninin, N550 yanıtı varlığında görüldüğü bildirilmiştir (35). Başka bir çalışmada P450 yanıtının kararlı bir bileşen olmadığı, N350 ve N550 arasında basitçe bulunduğu, N550 yanıtı net bir şekilde ortaya çıkmadığında P450 yanıtının da görülmediği belirtilmiştir (18). P450 bileşeni genliğinin uyaran özeliklerinden ve dikkatten etkilendiği gösterilmiştir (35). P450 bileşeni genliğinin uyaran özeliklerinden ve dikkatten etkilenmediği gösterilmiştir $(11,36)$. Evre 1 ve Evre 2'de uyarandan $400 \mathrm{~ms}$ sonra ortaya çıkan pozitif bileşenin (P450) uyanıklıktaki P300 olduğu ileri sürülmüştür (35). NREM'de P300 bileşeninin olamayacağını öne sürülmüş̧ür. P450, K-kompleksinin bileşeni olarak kabul edilmiştir (37).

N550 ve P900 bileşenlerinin benzer topografik dağılıma sahip olduğu gösterilmiştir $(38,39)$. N550 ve P900 bileşenlerinin topografik dağılımları ile ilgili çalışmada bu bileşenlerin farklı evrelerde farklı desenlere sahip olduğu gösterilmiş ve bu bileşenlerin farklı kaynaklara sahip olduğu iddia edilmiştir. P900 genliğinin uyku derinleştikçe arttığı raporlanmıştır (34). 
Ağrısız dokunsal uyaranlar ile yapılan çalışmada farklı frekans bantlarında yanıtlar incelenmiştir (5). Delta frekans bandında $(0,5-$ $3,5 \mathrm{~Hz}$ ) hedef ve hedef olmayan uyaranlar arasında anlamlı farklılık olduğu, ancak teta frekans bandında $(4-7 \mathrm{~Hz})$ hedef ve hedef olmayan uyaranlara karşı oluşan yanıtlar arasında anlamlı farklılık olmadığı belirtilmiştir. Aynı çalışmada santral bölgede meydana gelen yanıtların en büyük genliğe sahip olduğu, santral ve frontal bölgelerde meydana gelen yanıtların genliklerinin oksipital, pariyetal ve temporal bölgelerde meydana gelen yanıtların genliklerinden daha büyük olduğu öne sürülmüştür (40).

Erken latanslı somatosensoriyel uyarılma potansiyellerine karşı oluşan yanıtların ve olay ilişkili potansiyel uyaranlarına karşı oluşan yanıtların bilişsel işlemlemeyi yansıttığı belirtilmiştir (41). Uyanıklık ve uykuda katılımcıların sol işaret parmağına ağrılı (14$16 \mathrm{~mA}$ ) ve ağ $ı s ı z ~(3-4 \mathrm{~mA})$ uyaranların uygulandığı çalışmada N20, P30, N130, P240 bileşenleri incelenmiştir. N130 ve P240 bileşenlerinin sadece ağrılı uyaranlara uygulandığında görüldüğü ve uyku sırasında genliklerinde küçülme olduğu gösterilmiştir. N20 ve P30 bileşenlerinin ise uyaranın özelliğinden etkilenmediği uyku ve uyanıkııkta genlikleri arasında fark olmadığı belirtilmiştir (42). Elektriksel uyaranın uygulandığı bir çalışmada uyku ve uyanıklık süreçleri incelenmiştir. Uyanıklıkta iki farklı oturum yapılmış ve bir oturumda katılımcıların uyaranları saymaları istenirken diğer oturumda uyaranlara dikkat etmemeleri istenmiştir. Söz konusu iki oturumda iki hemisferde benzer sonuçlara ulaşıldığı ve dikkat koşulunda diğer koşula göre yanıtların ortaya çıkma sürelerinde anlamlı farklılık olduğu öne sürülmüştür. Uyku sürecinde kontrol grubunun yanıtlarının ortaya çıkma sürelerinin diğer gruba göre daha erken olduğu ve ağrı bileşeni ile uyku sırasında kortikal aktivasyonun önemli derecede azaldığı bulunmuştur (43).

Yüksek ve düşük tonların uygulandığı bir çalışmada bir gruptan uyumadan önce hedef seslerde ellerini kaldırmaları istenirken, diğer grubun ise sesleri sadece dinlemeleri istenmiştir. Bu çalışmada Evre 1'in başlarında hedef uyaranlara karşı oluşan yanıtlarda P300 bileşeni görülürken Evre 2'de görülmediği belirtilmiştir (11).

Literatürde bazı olay ilişkili potansiyel çalışmalarında Evre 1 dışında P300 bileşeni gösterilememiştir $(44,45)$. Bastuji ve ark. yaptıkları bir çalışmada Evre 1'de P300 olduğunu ileri sürmüşlerdir (43). Sıklığı ve yoğunluğu çok farklı iki uyaran tipiyle yapılan bir çalışmada uyanıklıktaki P300 bileşeninin zayıflamış halde Evre 2'de görüldüğü belirtilmiştir (45).

\section{Sonuç}

Dokunsal olay ilişkili potansiyel uyaranlarına karşı oluşan yanıtlar tüm kafada yaygın bir şekilde gözlenmiştir. Uykuda beyin yanıtlıığı sürmekte ancak elektrofizyolojik yanıtların oluşum biçimleri değişiklik göstermektedir. Ayrıca, uykuda yönlendirilmiş dikkat, uyaran ayırt etme, çalışan bellek gibi süreçlerin istemli olarak kullanılamaması seyrek ve sık uyaranlara karşı olan yanıtların birbirine benzer olmasına neden olmaktadır.

\section{Teşekkür}

Yazarlar, deney deseninin hazırlanmasındaki katkılarından ötürü Çağdaş Güdücü ve Uğraş Erdoğan'a, kayıtların alınmasındaki desteklerinden ötürü Ecem Olçum'a, Merve Tetik'e ve Ö. Tuğçe Bezircioğlu'na teşekkür etmektedirler.

\section{Kaynaklar}

1. Gokçay B, Arda B. Tıp tarihi açısından uyku ve uyku araştırmaları. Lokman Hekim Journal 2013;3:70-8.

2. Öztura I. Polisomnografi. Dokuz Eylül Üniversitesi Tıp Fakültesi Dergisi Uyku Bozuklukları Özel Sayısı 2005;7-12.

3. Iber C, Ancoli-Israel S, Chesson AJ, Quan SF. The AASM manual for the scoring of sleep and associated events: Rules, terminology and technical specifications. American Academy of Sleep Medicine, Westchester: Illionis. 2007.

4. Gazzaniga MS. The Ethical Brain. Dana Press, New York. 2005.

5. Öniz A. Beyinde delta, teta ve alfa osilasyon yanıtlarının ışığında öğrenme süreçleri. DEÜ Biyofizik Doktora Tezi. 2006.

6. Terney D, Beniczky S, Varga ET, Keri S, Nagy HG, Vecsei L. The effect of sleep deprivation on median nerve somatosensory evoked potentials. Neurosci Lett 2005;383:82-6.

7. Wang X, Inui K, Qiu Y, Kakigi R. Effects of sleep on cortical responses to noxious stimuli. Int Congr Ser 2005;1278:356-62.

8. Aydın H. Uyku yapısı ve işlevi. (2008) İçinde: Karakaş S, İkeç C, İşeri E, Karakaş HM, Yüksel N, Arıkan O, Uzbay IT, Özgören M, editors. Kognitif nörobilimler. MN Medikal \&Nobel, Ankara, syf: 281-302.

9. Atienza M, Cantero JL, Escera C. Auditory information processing during human sleep as revealed by event related brain potentials. Clin Neurophysiol 2001;112:2031-45.

10. Harsh J, Voss U, Hull J, Schrepfer S, Badia P. ERP and behavioral changes during the wake/sleep transition. Psychophysiology 1994;31:244-52.

11. Jones BE. Paradoxical sleep and its chemical/structural substrates in the brain. Neuroscience 1991;40:637-56.

12. Bradley C, Meddis R. Arousal threshold in dreaming sleep. Physiological Psychology 1974;2:109-10.

13. Burton S, Harsh J, Badia P. Cognitive activity in sleep and responsiveness to external stimuli. Sleep 1988;11:61-8.

14. Elberling C, Bak C, Kofoed B, Lebech J, Saermark K. Auditory magnetic fields: Source localization and "tonotopical organization" in the right hemisphere of the human brain. Scand Audiol 1982;11:61-5.

15. Elton M, Winter O, Heslenfeld D, Loewy D, Campbell K, Kok A. Event related potentials to tones in the absence and presence of sleep spindles. J Sleep Res 1997;6:78-83.

16. Colrain IM, Di Parsia P, Gora J. The impact of prestimulus EEG frequency on auditory evoked potentials during sleep onset. Can J Exp Psychol 2000;54:243-54.

17. Yang CM, Wu CS. The effects of sleep stages and time of night on NREM sleep ERPs. Int J Psychophysiol 2007;63:87-97.

18. Plihal W, Weaver S, Molle M, Fehm HL, Born J. Sensory processing during early and late nocturnal sleep. Electroencephalogr Clin Neurophysiol. 1996;99:247-56.

19. Nittono $H$, Momose $D$, Hori T. The vanishing point of the mismatch negativity at sleep onset. Clin Neurophysiol 2001;112:732-9.

20. Cote KA, Campbell KB. The effect of varying stimulus intensity on P300 during sleep. Neuroreport 1999;10:2313-8.

21. Bastuji H, Garcia-Larrea L. Evoked potentials as a tool for the investigation of human sleep. Sleep Med Rev 1999;3:23-45.

22. Peszka J, Harsh J. Effect of sleep deprivation on NREM sleep ERPs and related activity at sleep onset. Int J Psychophysiol 2002;46:275-86.

23. Bastien C, Campbell K. The evoked Kcomplex: All-or-none phenomenon? Sleep 1992;15:236-45.

24. Voss $U$, Harsh J. Information processing and coping style during the wake/sleep transition. J Sleep Res 1998;7:225-32.

25. Bastien C, Campbell KB. The evoked K-complex: all or none phenomenon. Sleep 1992;15:236-45.

26. Colrain IM, Webster KB, Hirst G. The N550 component of the evoked K-complex: a modality non-specific responses. J Sleep Res 1999;8:273-80. 
27. Nicholas CL, Trinder J, Crowley KE, Colrain IM. The impact of slow wave sleep proximity on evoked K-complex generation. Neurosci Lett 2006;404:127-31.

28. Bastien C, Campbell K. Effects of rate of tone-pip stimulation on the evoked K-complex. J Sleep Res 1994;3:65-72.

29. Colrain IM. The K-complex: a 7-decade history. Sleep 2005;28:255-73.

30. Yang CM, Wu CS. The effects of sleep stages and time of night on NREM sleep ERPs. Int J Psychophysiol 2007;63:87-97.

31. Colrain IM, Di Parsia P, Gora J. The impact of prestimulus EEG frequency on auditory evoked potentials during sleep onset. Can J Exp Psychol 2000;54:243-54.

32. Colrain IM, Webster KB, Hirst G. The N550 component of the evoked K-complex: a modality non-specific responses. J Sleep Res 1999;8:273-80.

33. Cote KA, De Lugt DR, Langley SD, Campbell KB. Scalp topography of the auditory evoked K-complex in stage 2 and slow wave sleep. J Sleep Res 1999;8:263-72.

34. Nielsen-Bohlman L, Knight RT, Woods DL, Woodward K. Differential auditory processing continues during sleep. Electroencephalogr Clin Neurophysiol 1991;79:281-90.

35. Hull, Harsh J. P300 and sleep-related positive waveforms (P220, P450, and P900) have different determinants. J Sleep Res 2001;10:9-17.

36. Kotchoubey B. Event-related potential measures of consciousness: two equations with three unknowns. Prog Brain Res 2005;150:427-44.
37. Bastien C, Campbell K. The evoked K-complex: all-or-none phenomenon? Sleep 1992;15:236-45.

38. Bastien C, Campbell K. Effect of rate of tone-pip stimulation on the evoked K-complex. J Sleep Res 1994;3:65-72.

39. Wesensten NJ, Badia AP. The P300 component in sleep. Physiol Behav 1988;44:215-20.

40. Nakao M, Barsky AJ, Nishikitani M, Yano E, Murata K. Somatosensory amplification and its relationship to somatosensory, auditory, and visual evoked and event-related potentials (P300). Neurosci Lett 2007; 415:185-9.

41. Wang X, Inui K, Qiu Y, Hoshiyama M, Tran TD, Kakigi R. Effect of sleep on pain-related somatosensory evoked potentials in humans. Neurosci Res 2003;45:53-7.

42. Wang X, Inui K, Qiu Y, Kakigi R. Effect of sleep on cortical responses to noxious stimuli. Neuroscience 2004;128:177-86.

43. Bastuji H, Garcia L, Franc C, Mauguiere F. Brain processing of stimulus deviance during slow-wave and paradoxial sleep: a study of human auditory evoked responses using the oddball paradigm. J Clin Neurophysiol 1995;12:155-67.

44. Niiyama H, Fujiwara R, Sato N, Hishikawa Y. Endogenous components of event-related potential appearing during NREM stage 1 and REM sleep in man. Int J Psychophysiol 1994;17:165-74.

45. Salinbury D, Squires NK, Ibel S, Maloney T. Auditory event related potentials during stage 2 NREM sleep in human. J Sleep Res 1992;1:251-7. 